\title{
Characterizing lunch meals served and consumed by pre-school children in Head Start
}

\author{
Theresa A Nicklas ${ }^{1, *}$, Yan Liu' ${ }^{1}$, Janice E Stuff ${ }^{1}$, Jennifer O Fisher ${ }^{2}$, Jason A Mendoza ${ }^{1}$ \\ and Carol E O'Neil ${ }^{3}$ \\ 'Department of Pediatrics, USDA/ARS Children's Nutrition Research Center at Baylor College of Medicine, \\ 1100 Bates Avenue, Houston, TX 77030, USA: ${ }^{2}$ Department of Public Health, Temple University, Philadelphia, \\ PA, USA: ${ }^{3}$ Louisiana State University Agricultural Center, Baton Rouge, LA, USA
}

Submitted 24 July 2012: Final revision received 19 March 2013: Accepted 11 April 2013: First published online 24 May 2013

\begin{abstract}
Objective: To examine the variability of food portions served and consumed by African-American and Hispanic-American pre-school children attending Head Start.

Design: Cross-sectional.

Setting: Food consumption by pre-schoolers ( $n$ 796) enrolled in sixteen Head Start centres in Houston, Texas (51\% boys, $42 \%$ African-American, mean age 4 years) were assessed during $3 \mathrm{~d}$ of lunch meals using digital photography. Descriptive statistics and multilevel regression models, adjusting for classroom and school clustering effects, were determined.

Subjects: Head Start pre-schoolers aged 3-5 years.

Results: Mean amount served was $2428 \mathrm{~kJ}(580 \mathrm{kcal})$ and $572 \mathrm{~g}$. Mean intake was $1421 \mathrm{~kJ}(339 \mathrm{kcal})$ and $331 \mathrm{~g}$ : $20 \%$ protein, $46 \%$ carbohydrate and $34 \%$ fat. Plate waste was $43 \%$ (range: $38 \%$ (fruit) to $61 \%$ (vegetables)). Mean CV of food served was 29\%: 33\% for entrées, $44 \%$ for vegetables, $60 \%$ for fruit and $76 \%$ for starches. Mean CV of food consumed was 46\%: 58\% for entrées, $86 \%$ for fruit, $96 \%$ for vegetables and $111 \%$ for starches. Total gram amount of food served was positively correlated with consumption $(r=0 \cdot 43, P<0 \cdot 001)$.

Conclusions: Plate waste and variation in amounts served and consumed were substantial; amounts served were associated with amounts consumed. Large portion sizes may contribute to paediatric obesity by promoting excessive intake at meals. Understanding factors influencing portion sizes provides insight about specific intervention strategies that can be used in obesity prevention programmes.
\end{abstract}

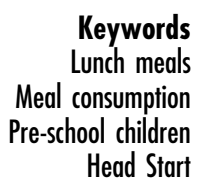

Keywords Lunch meals Meal consumption Head Start
Childhood obesity is a major public health problem. The National Health and Nutrition Examination Survey (NHANES) 2009-2010 data showed that nearly 15\% of US children aged 2-5 years were overweight, while $12 \%$ were obese ${ }^{(1)}$. Key contributing factors to overweight and obesity in children have not been determined; however, most experts agree that weight gain occurs when dietary intake exceeds energy expenditure. Children's eating patterns are initiated early in life (i.e. at age $2-5$ years), suggesting that the pre-school period is a pivotal developmental time point during which healthful eating patterns may be fostered ${ }^{(2-6)}$.

Child-care settings are an increasingly important social environment in which food-related behaviours develop, since up to $60 \%$ of young children are cared for in these settings and thus eat outside their parents' care ${ }^{(7)}$. Head Start (HS) is a US federal child-care programme that provides comprehensive services to children of preschool age and their families who have incomes below the federal poverty level ${ }^{(8)}$. HS programmes are expected to encourage family-style meal service to allow children to: (i) identify and be introduced to new foods, tastes and new menus; (ii) choose the amount of food they want to have on their plate; and (iii) practise good table manners and new skills with their hands and fingers ${ }^{(9)}$.

Child-care feeding practices have important implications for the development of eating patterns, including practices involving portion size; however, little is known about the characteristics of the eating environment and its potential effect on weight status ${ }^{(10)}$. Young children demonstrate self-regulation of short-term energy intake but environmental cues regarding food intake can override this ability ${ }^{(11-13)}$. Exposure to large portion sizes is one strong environmental cue that is positively associated with increased energy intake in population-based and experimental studies of children ${ }^{(11,14-20)}$.

Large portion sizes may contribute to the high prevalence of overweight among children by promoting excessive intake at meals ${ }^{(11,17-21)}$. Studies have shown 
that increased portion sizes of energy-dense foods promoted increased intake of those foods and were positively related to body weight ${ }^{(14,16,22)}$. The effects of large portions on intake may extend to fruits and vegetables and encourage increased consumption ${ }^{(23,24)}$. Children's intake of fruits and vegetables remains low and does not meet the daily recommendation ${ }^{(25,26)}$. That fruit and vegetable intake has been inversely related to body weight in some adult studies suggests that low intake might also place children at increased risk for obesity, as well as for cancer and other chronic diseases later in life ${ }^{(27)}$.

More studies are needed to better understand factors that influence portion sizes of a variety of foods, in an effort to decrease the excessive intake of energy-dense foods and increase the consumption of fruits and vegetables ${ }^{(28-30)}$. Little is known about food portions served and the amount of plate waste in meals served to young children in day care. It is unknown whether variations in portion sizes of fruits and vegetables have a beneficial effect on children's intake of those foods. Therefore the primary goal of the present study was to examine the variability in the portions of foods served and consumed by African-American and Hispanic-American children of pre-school age attending HS. A secondary goal was to examine whether child characteristics were associated with the amount of total food served and consumed by the children at the lunch meal.

\section{Experimental methods}

\section{Lunch meals at Head Start}

All participating HS centres provided family-style lunch meals where children served themselves the food offered at that meal. On rare occasions the teacher helped with serving the food to the children. The kinds of foods served at the lunch menu were required to meet minimum standards recommended in the Child and Adult Care Food Program (CACFP) ${ }^{(31)}$ meal pattern requirements. Given that the children served themselves, the amount of food served and consumed by each child varied. Thus, the amounts served reflected the self-service amounts.

\section{Food consumed}

Digital photography ${ }^{(32)}$ was used to measure $3 \mathrm{~d}$ of lunch meal intake for each child participating in the study. To examine the types of foods that were offered and consumed, foods were categorized into six different food groups: entrées, starches, vegetables, fruit, beverages and condiments. Prior to lunch, the children were briefly told that the research staff would be taking pictures of the food on their plate. For the diet assessment, the plate of food was photographed with a digital camera, and any second servings and plate waste were also photographed during or after the meal. The foods were photographed with a digital camera mounted on a tripod with the lens

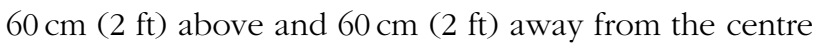
of the meal plate with a camera angle of $45^{\circ}$. A place mat with marked regions for placement of the meal plate was fixed to the table supporting the camera tripod to ensure optimal visibility of the meal plate. The same camera angle and distance from foods were used throughout, so that the apparent size of all foods remained constant across the photographs. While in the dining location, photographs of weighed reference portions of the food choices available to the children on each day of data collection were also taken ${ }^{(33)}$. The reference portions of foods were the standards used to determine the amount of foods that were on the filled plates.

In the laboratory, a computer application was used to simultaneously display the digital photographs of the reference portions and meal plate showing either food selection or plate waste. Trained research staff estimated the percentage of the reference portion of the food selections, any second helpings and plate waste.

The trained estimators were not the same staff who did the nutrient coding. To derive the energy and nutrient contents for each food served in the HS centres during the study, foods were coded using the Nutrition Data SystemResearch (NDSR) dietary analysis program version 2006 (Nutrition Coordinating Center, University of Minnesota, Minneapolis, MN, USA). The HS staff provided recipes, labels and preparation of food items. For mixed dishes, an attempt was made to match the food to a similar food item in NDSR. If no match was available, the components of the recipe were coded. The food groups used in the present study reflect the CACFP meal pattern requirements ${ }^{(31)}$ for those specific food groups. For each food item, the nutrient content was expressed per gram and was multiplied by the gram weight for portion size, plate waste and food intake for each child. Results for macronutrients in each food's portion size, plate waste and intake were downloaded and merged with other variables in the master database.

The digital photography method has been found to be reliable and accurate when used to measure the food intake of pre-school children. Mean differences between directly weighed foods and the digital photography method range from $<6 \mathrm{~g}$ to $11 \mathrm{~g}$; agreement is consistently high among the research staff who estimate portion sizes; and the overall portion size estimates highly correlate with weighed portion sizes ( $r$ values range from $0 \cdot 77$ to $0 \cdot 96)^{(33)}$.

\section{Antbropometrics}

Duplicate heights and weights were obtained following a standardized protocol which included quality control procedures $^{(34)}$. Heights and weights of the teachers and children were obtained by trained research staff at the HS centre and the average values were used in the present study.

\section{Demographics}

A demographic questionnaire (e.g. age, ethnicity) was completed by the teachers at the HS centre. For the 
children, both the research staff and the teachers mutually completed the demographics questionnaire for each child participant.

\section{Statistical analyses}

All statistical analyses were run using the SAS statistical software package version $9 \cdot 2$. Weight and height status of the children were measured, from which BMI were calculated as weight (in kilograms) divided by the square of height (in metres) and converted to age- and genderappropriate BMI Z-scores or percentiles from the Centers for Disease Control and Prevention Reference Standards ${ }^{(35)}$.

Means and standard deviations, as well as the frequency distribution of participant characteristics, and the amounts of food served, plate waste and food consumed were calculated and then averaged for each food group (fruits, vegetables, entrées, milk, condiments and starches) and for all foods together. Energy density was defined as mean energy content per weight of food $(\mathrm{kJ} / \mathrm{g})$ consumed at the lunch meal. Post hoc comparisons for total energy from food intake and total amount of food consumed were examined across energy density tertiles. Plots and histograms of residuals were used to investigate homogeneity of variance and normal distribution of variables. $P<0.05$ was considered statistically significant. A Bonferroni correction was used to adjust the significance level for multiple comparisons.

Multilevel modelling was necessary to account for cluster effects and to provide greater efficiency because the children were nested within teachers/classrooms and teachers/classrooms were nested within schools/centres. Three-level hierarchical models were performed to assess whether selected demographic characteristics of the children were associated with the amount of food served, plate waste and intake. Demographic characteristics included gender, ethnicity/race, age and BMI $Z$-score as first level (children), while teachers' characteristics included ethnicity/race, age and BMI as second level, and schools/centres as third level.

\section{Results}

The study included pre-school children ( $n$ 796) attending HS ( $51 \%$ boys, $42 \%$ African-American and $58 \%$ HispanicAmerican). Thirty-nine per cent of the children were overweight or obese. The children were recruited from 149 classrooms within sixteen HS centres in Houston, Texas. Consent forms were sent home with the children for parents to sign for their child (passive consent). Active consent was received for the teachers participating in the study.

The mean amount of food in lunch meals served and consumed by food type is shown in Table 1 . The mean amount of food $/ \mathrm{milk}$ served was $572 \mathrm{~g}$ ( $58 \%$ food). The mean amount of food/milk plate waste was $240 \mathrm{~g}$; thus $331 \mathrm{~g}$ were consumed. The mean amounts of food/milk

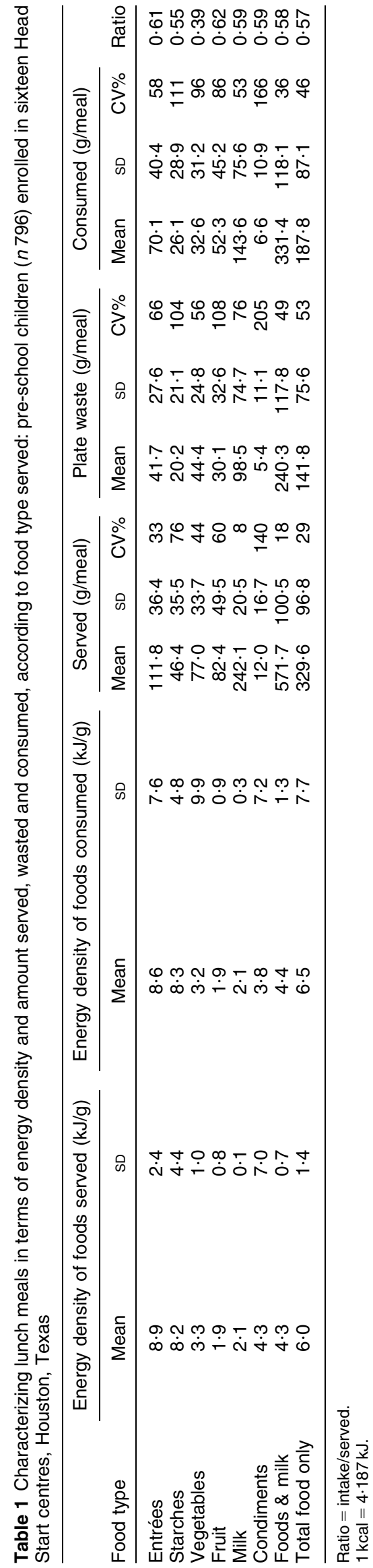


served to pre-schoolers at the lunch meal were comparable to the CACFP requirements ${ }^{(31)}: 2.54$ ounces for the entrée (meat/meat alternate), 0.77 ounces for the starch (grains/bread), 0.59 cups for the vegetables, 0.54 cups for the fruit and 1.07 cups for the milk food components (data not shown). However, the CV of the amount of food/milk served by food type varied considerably: $44 \%$ for vegetables, $76 \%$ for starch, $8 \%$ for milk, 33\% for entrées and $60 \%$ for fruit. Only $57 \%$ of the total food served was actually consumed. Plate waste was highest for vegetables (61\%) and lowest for fruit (38\%) and entrées (39\%). The energy density of the food served and consumed was highest for entrées and starches and lowest for fruit and milk.

The macronutrient composition of the lunch meal served and consumed is shown in Table 2. The mean energy intake from the lunch meal was $1421 \mathrm{~kJ}$ (339 kcal). The macronutrient percentage of total energy was $21 \%$ protein, $46 \%$ carbohydrate and 34\% fat. Figure 1 shows the relationship between the total amount of food served and the total amount of food consumed. There was a significant $(P<0 \cdot 0001)$ linear increase in the food served and the amount of food consumed (Fig. 1). This was true for all food categories. There was a significant $(r=0 \cdot 43$, $P<0.001)$ correlation between the total amount served and the amount consumed, ranging from $0 \cdot 71$ (vegetables, $P<0 \cdot 0001$ ) to $0 \cdot 80$ (starches, $P<0 \cdot 0001$ ).

There were significant linear relationships between the total energy intake from food, energy density and the amount of food consumed by the children at the lunch meal (Fig. 2). For the lowest tertile of energy density of total food consumed, there was a significantly lower total

Table 2 Macronutrient composition of lunch meals served and consumed by pre-school children ( $n$ 796) enrolled in sixteen Head Start centres, Houston, Texas

\begin{tabular}{|c|c|c|c|c|c|c|c|c|c|c|}
\hline \multirow[b]{2}{*}{ Macronutrient } & \multicolumn{3}{|c|}{ Served } & \multicolumn{3}{|c|}{ Plate waste } & \multicolumn{3}{|c|}{ Consumed } & \multirow[b]{2}{*}{ Ratic } \\
\hline & Mean & SD & CV\% & Mean & SD & CV\% & Mean & SD & CV\% & \\
\hline Energy (kJ) & 2428 & 549 & 23 & 1008 & 499 & 49 & 1421 & 555 & 39 & 0.58 \\
\hline Protein (g) & $29 \cdot 1$ & $7 \cdot 1$ & 24 & $11 \cdot 6$ & $5 \cdot 7$ & 49 & $17 \cdot 5$ & $7 \cdot 7$ & 44 & 0.59 \\
\hline Carbohydrate (g) & $66 \cdot 9$ & $17 \cdot 2$ & 26 & $28 \cdot 1$ & $14 \cdot 9$ & 53 & $38 \cdot 8$ & $15 \cdot 9$ & 41 & 0.58 \\
\hline Fat $(\mathrm{g})$ & $22 \cdot 3$ & $7 \cdot 6$ & 34 & $9 \cdot 4$ & $5 \cdot 8$ & 62 & $12 \cdot 9$ & $6 \cdot 4$ & 50 & 0.58 \\
\hline
\end{tabular}

Ratio $=$ intake/served.

$1 \mathrm{kcal}=4 \cdot 187 \mathrm{~kJ}$.

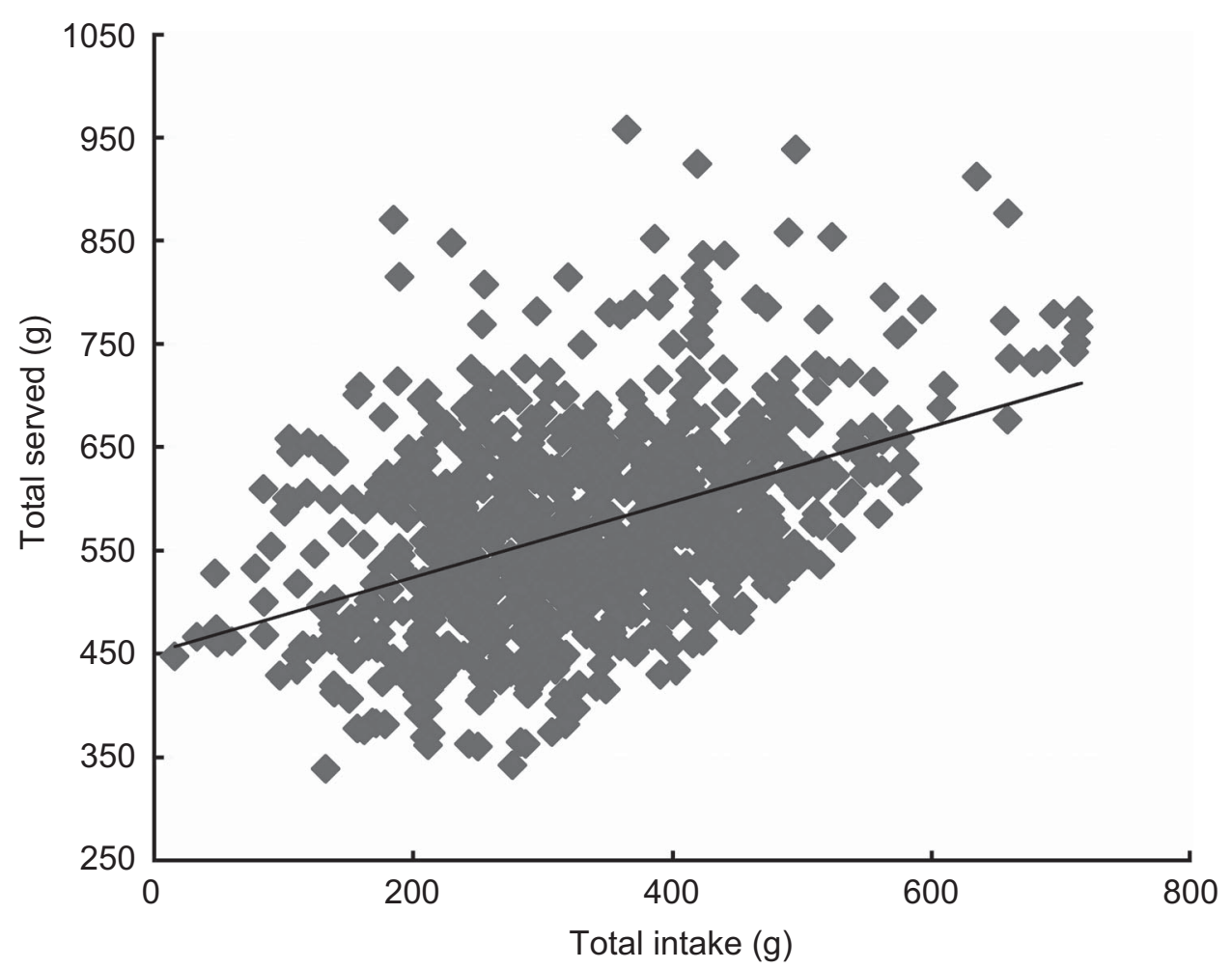

Fig. 1 Association between lunch meals served and consumed by pre-school children ( $n$ 796) enrolled in sixteen Head Start centres, Houston, Texas. Total intake $=43 \cdot 6+0.50 \times$ total served; $R^{2}=0 \cdot 18, P<0.0001$ 
(a)

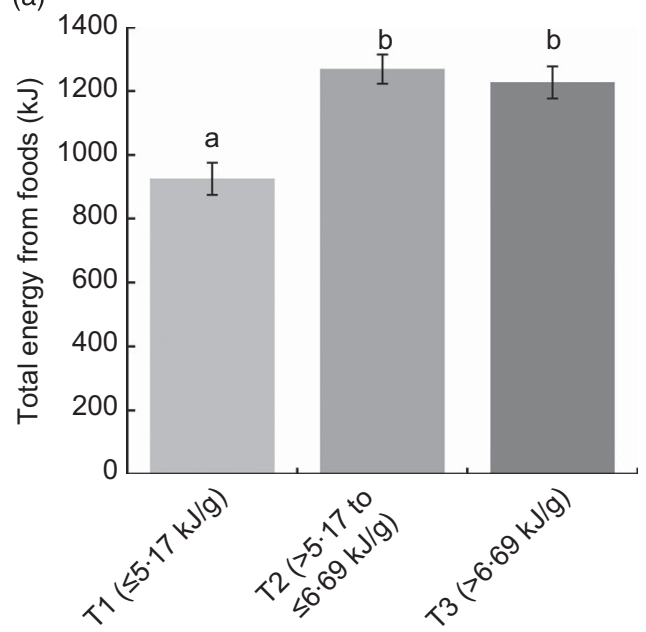

Energy density tertile (b)

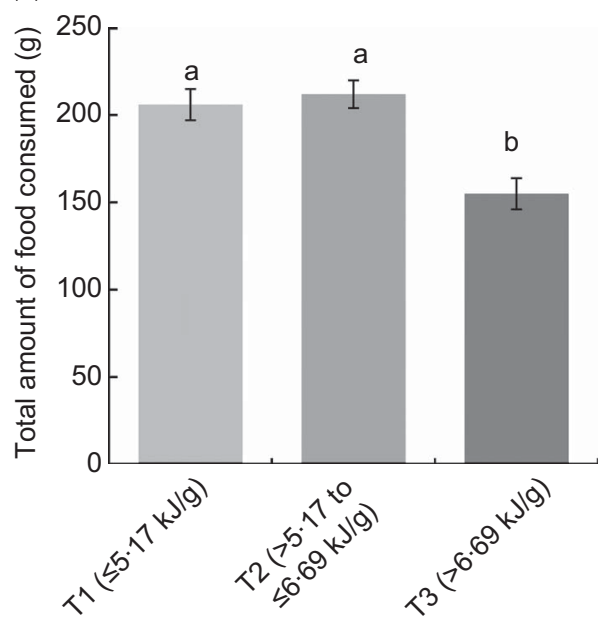

Energy density tertile

Fig. 2 Relationship of (a) energy intake from foods and (b) amount of food consumed at the lunch meal with energy density among pre-school children $(n 796)$ enrolled in sixteen Head Start centres, Houston, Texas. Values are means with their standard errors represented by vertical bars. ${ }^{a, b}$ Mean values with unlike superscript letters were significantly different $(P<0.0001)$. $1 \mathrm{kcal}=4 \cdot 187 \mathrm{~kJ}$

Table 3 Mean variation in amount of food served and consumed at lunch meals by child characteristics: pre-school children ( $n$ 796) enrolled in sixteen Head Start centres, Houston, Texas

\begin{tabular}{|c|c|c|c|c|c|c|c|c|c|}
\hline \multirow[b]{2}{*}{ Child characteristic } & \multicolumn{3}{|c|}{ Served (g/meal) } & \multicolumn{3}{|c|}{ Plate waste (g/meal) } & \multicolumn{3}{|c|}{ Consumed (g/meal) } \\
\hline & LSM & $\mathrm{SE}$ & Overall $P$ value & LSM & $\mathrm{SE}$ & Overall $P$ value & LSM & SE & Overall $P$ value \\
\hline \multicolumn{10}{|l|}{ Ethnicity/racet } \\
\hline Hispanic-American & $573 \cdot 1$ & $18 \cdot 4$ & $<0.01$ & $224 \cdot 8$ & $19 \cdot 6$ & & $345 \cdot 3$ & $12 \cdot 5$ & $<0.01$ \\
\hline African-American & $591 \cdot 7$ & $18 \cdot 5$ & & $220 \cdot 6$ & $19 \cdot 8$ & & $377 \cdot 6$ & $13 \cdot 0$ & \\
\hline \multicolumn{10}{|l|}{ Genderł } \\
\hline Male & $580 \cdot 6$ & $18 \cdot 2$ & & $214 \cdot 2$ & $19 \cdot 4$ & $<0.01$ & $367 \cdot 8$ & $12 \cdot 3$ & \\
\hline Female & $584 \cdot 1$ & $18 \cdot 2$ & & $231 \cdot 1$ & $19 \cdot 4$ & & $355 \cdot 1$ & $12 \cdot 1$ & \\
\hline \multicolumn{10}{|l|}{ BMI Z-score§ } \\
\hline$<85$ th & $580 \cdot 0$ & $18 \cdot 1$ & & $246 \cdot 0^{\mathrm{a}, \mathrm{b}}$ & $19 \cdot 2$ & $<0.0001$ & $334 \cdot 7^{a, b}$ & $11 \cdot 7$ & $<0.0001$ \\
\hline$\geq 85$ th to $<95$ th & $581 \cdot 5$ & $18 \cdot 5$ & & $232 \cdot 0^{\mathrm{b}}$ & $20 \cdot 0$ & & $352 \cdot 9^{b}$ & $13 \cdot 5$ & \\
\hline$\geq 95$ th & $585 \cdot 6$ & $18 \cdot 6$ & & $190 \cdot 0^{\mathrm{c}}$ & $20 \cdot 1$ & & $396 \cdot 8^{\mathrm{c}}$ & $13 \cdot 7$ & \\
\hline Linear trend ( $P$ value) & & & & $<0.0001$ & & & $<0.0001$ & & \\
\hline \multicolumn{10}{|l|}{ Age (years)\| } \\
\hline$\leq 4$ & $572 \cdot 3$ & $18 \cdot 3$ & & $256 \cdot 3^{a}$ & $19 \cdot 5$ & $<0.0001$ & $309 \cdot 8^{a}$ & $12 \cdot 4$ & $<0.0001$ \\
\hline$>4$ to $\leq 5$ & $583 \cdot 8$ & $18 \cdot 3$ & & $228 \cdot 2^{\mathrm{b}}$ & $19 \cdot 4$ & & $358 \cdot 8^{b}$ & $12 \cdot 2$ & \\
\hline$>5$ & $591 \cdot 0$ & $19 \cdot 4$ & & $183 \cdot 4^{\mathrm{C}}$ & $21 \cdot 3$ & & $415 \cdot 7^{\mathrm{c}}$ & $15 \cdot 6$ & \\
\hline Linear trend ( $P$ value) & $<0.05$ & & & $<0.0001$ & & & $<0.0001$ & & \\
\hline
\end{tabular}

LSM, least square mean.

${ }^{a, b, c}$ Mean values within a column with unlike superscript letters were significantly different (Bonferroni correction $P<0 \cdot 0167$ ).

tControlling for child's gender, age and BMI Z-score and teacher's ethnicity/race, age and BMI.

¥Controlling for child's ethnicity/race, age and BMI Z-score and teacher's ethnicity/race, age and BMI.

§Controlling for child's ethnicity/race, gender and age and teacher's ethnicity/race, age and BMI.

IIControlling for child's ethnicity/race, gender and BMI Z-score and teacher's ethnicity/race, age and BMI.

energy intake from food $(P<0 \cdot 0001)$ and a significantly higher total amount of food consumed $(P<0 \cdot 0001)$, compared with the middle-to-upper energy density tertiles.

Several child characteristics were associated with the amount of total food served and consumed at the lunch meal (Table 3). African-American children served themselves more food than Hispanic-American children $(P=0 \cdot 007)$ and had significantly higher food intakes $(P=0 \cdot 0014)$. Although the amount of food the children served themselves did not vary by BMI, the heavier children were more likely to consume larger amounts of food $(P$ trend $<0 \cdot 0001)$. There was a linear increase in the total amount of food consumed by age ( $P$ trend $<0 \cdot 0001$ ). The oldest children (5 years) consumed $106 \mathrm{~g}$ more food than the youngest children (3 years).

There was considerable variation in the mean amount of food/milk served at the lunch meal across the sixteen HS centres (Fig. 3). The mean amount of food $/ \mathrm{milk}$ 


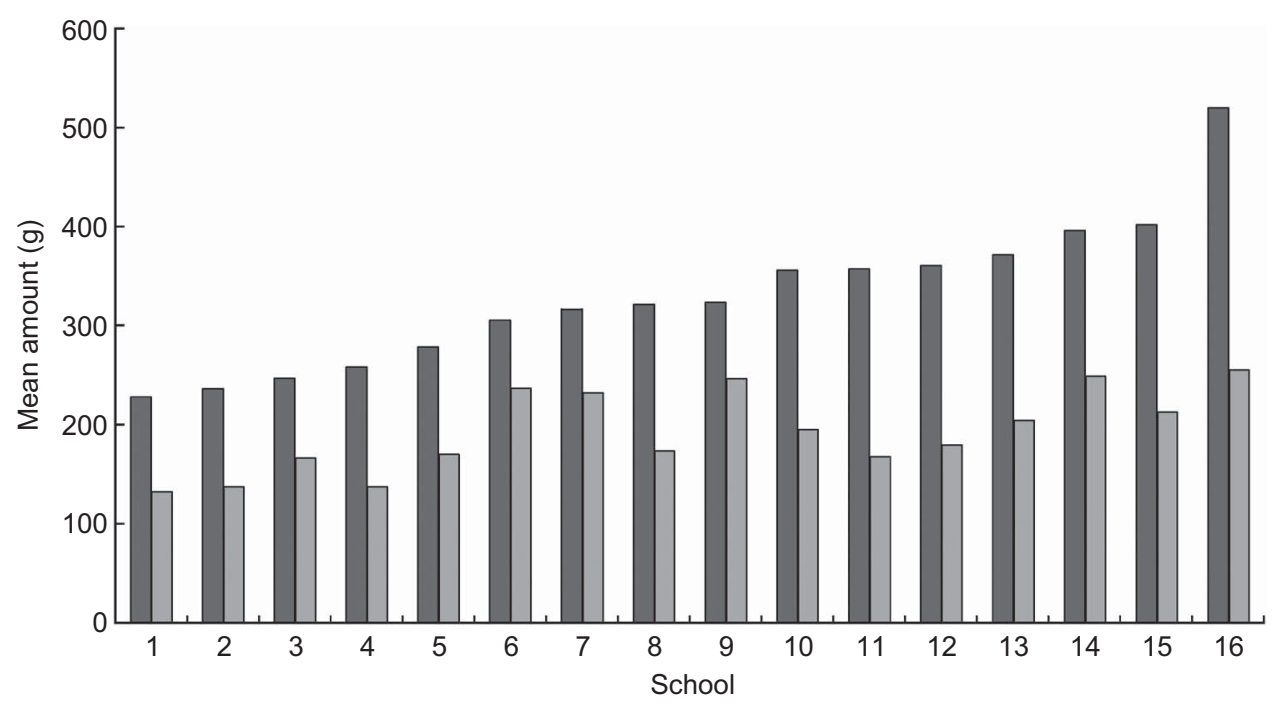

Fig. 3 Variation (intra-class correlation) in lunch meals served and consumed among pre-school children ( $n$ 796) enrolled in sixteen Head Start centres, Houston, Texas. $\square$, amount served (mean range 228-503 g, intra-class correlation coefficient between schools $=0.47 ; \square$, amount consumed (mean range $132-255 \mathrm{~g}$; intra-class correlation coefficient between schools $=0 \cdot 14$ )

served ranged from 228 to $503 \mathrm{~g}$ with an intra-class correlation coefficient of $0 \cdot 47$. The variation in the mean amount consumed across sixteen HS centres was much smaller. Mean intake ranged from 132 to $255 \mathrm{~g}$ with an intra-class correlation coefficient of $0 \cdot 14$.

\section{Discussion}

To our knowledge, the present study is the first to evaluate lunch meals by the amounts served and consumed by pre-school children in HS. Specifically, the amount of foods served was evaluated together with child characteristics as potential predictors for the amount of foods consumed. On average, the mean amount of foods $/ \mathrm{milk}$ served to pre-schoolers at the lunch meal was comparable to the CACFP requirements. However, the variation in the amount of foods served and consumed was substantial, particularly across the sixteen HS centres. Plate waste of the HS lunch meal was very high, with $43 \%$ of total food served not being consumed.

There was a significant correlation between the amount of food served and the amount consumed. This is consistent with the literature that children who received a larger portion of food consumed more food than if they received a smaller portion ${ }^{(11,17-20)}$. Children aged 3-5 years consumed $25 \%$ more of an entrée and 15\% more total energy at lunch when presented with portions that were double an age-appropriate standard size ${ }^{(17)}$. Despite the amount of food wasted, results suggested that larger portions resulted in increased intake. Food portions served have been positively related to body weight of 1-year-old children, where children with higher body weights consumed, on average, larger portions ${ }^{(14)}$. Similar results were found in the present study, in that obese children were more likely to consume larger amounts of food.

Intake of an entrée has been shown to be greater with large portions than with self-selected portions ${ }^{(17,20)}$. However, in the present study the portions served to the child were all self-selected portions but these varied considerably. Children generally selected portions of food that were equivalent to, or greater than, the minimum portion sizes specified in the CACFP meal pattern requirements ${ }^{(36)}$. Children generally consumed between 70 and $75 \%$ of the portions of food taken at lunch. Different types of foods were consumed in varying proportions, with $73 \%$ of the milk being consumed and only $59 \%$ of the vegetables ${ }^{(36)}$. The wide range of children's observed self-served portion sizes suggests that allowing children to self-serve may be less beneficial to some children than to others, since increased amounts of foods served were associated with increased intakes. This was true for the energy-dense foods but not the case with fruits and vegetables.

Total energy intake increased significantly with increased energy density of the total food consumed. Children who ate the lunch meal with the lowest energy density (tertile 1) consumed $925 \mathrm{~kJ}(221 \mathrm{kcal})$ compared with those in the upper tertile who consumed $1227 \mathrm{~kJ}$ $(293 \mathrm{kcal})$. An effect of meal energy density on energy intake is consistent with experimental and populationbased studies of energy density in children ${ }^{(28-30)}$. Further, in the present study total food intake (in grams) was also negatively associated with meal energy density, consistent with relationships reported in the Feeding Infants and Toddlers Study between energy density and food portions consumed ${ }^{(37)}$. Highly controlled experimental studies of energy density in children have demonstrated 
that the weight of food intake is not substantially altered by systematic changes to energy density, such that children consume greater amounts of energy when more energydense versions of foods are served ${ }^{(29,30,38)}$. Taken together, the findings of the present research suggest that HS children consume more energy at school meals when more energy-dense meals are offered.

Another key finding was the influence of age, ethnicity and BMI on portion size and young children's intake at the lunch meal. African-American children served themselves a larger amount of food than Hispanic-American children, resulting in significantly higher intakes. Older children consumed more total amount of food than younger children. The obese children consumed more total food than the overweight and normal-weight children, despite the finding that there was no difference in the amount that was served by weight status. In one study, the tendency to consume more when served large portions was not influenced by age, ethnicity or $\mathrm{BMI}^{(13)}$. However, populationbased studies suggest that family demographics, including income, ethnicity and education, may influence the extent to which children prefer and consume large portions ${ }^{(14,39)}$.

The mean energy and macronutrients from the lunch meal consumed are similar to levels reported for children aged 2-5 years from national surveys ${ }^{(40)}$. Pre-school children consumed an average of $1423 \mathrm{~kJ}$ ( $340 \mathrm{kcal})$ from the lunch meal and the percentage of protein, carbohydrate and fat did not exceed the Institute of Medicine's Acceptable Macronutrient Distribution Ranges ${ }^{(41)}$. A recent national survey showed that, on average, children in HS consumed adequate amounts of all key nutrients studied $^{(42)}$. However, compared with other low-income children of the same age, HS children were at greater risk for not meeting the RDA for total daily intake of thiamin, riboflavin, niacin and $\mathrm{Ca}$. Other studies have evaluated food intake of children at child-care centres ${ }^{(43,44)}$. They found that children aged 3 years consumed sufficient fruits and meat/alternates, but insufficient grains, vegetables or dairy to meet two-thirds of the Food Guide Pyramid recommendations for young children. The children aged 4 and 5 years only consumed the recommended amounts of dairy.

In the present study, the amount of food consumed by children at the HS lunch meal was assessed with a more precise method than the dietary methods used in other studies $^{(33,45-47)}$. The digital photography method has been used in a number of settings and its reliability and validity have been established in adults ${ }^{(45,48,49)}$, school-age ${ }^{(47,48,50)}$ and pre-school ${ }^{(33)}$ children. Portion size estimates correlate highly with weighed portion sizes ${ }^{(45)}$ and mean differences between directly weighed foods and digital photography estimates are minimal $(<6 \mathrm{~g})$ with no systematic bias over levels of food intake ${ }^{(45)}$. These results are consistent with those shown specifically with pre-school children ${ }^{(33)}$. In the NHANES, the nutritional intakes of pre-school children were assessed with parents serving as a proxy for their child's intake. Older studies have shown that parental recall of pre-school children's intake is a valid measure ${ }^{(51,52)}$; however, more recent studies show that parental recalls may overestimate what a child is consuming outside the home in day care ${ }^{(51-53)}$.

Our study found that the energy intake of the lunch meal consumed by children in the NHANES was comparable to what was actually served to the children in day care. Yet, with $43 \%$ plate waste found in the lunch meal at day care, children's energy intake from the lunch meal was actually $42 \%$ lower than the amount of energy served.

\section{Limitations}

Use of a convenience sample, such as the one used in the present study, has several inherent limitations including that the results may not be representative of pre-school children outside the Houston HS population and may be difficult to duplicate. Another limitation is that information on caregivers' behaviours related to child self-service was not collected and may have influenced the variability in the results. Data were also not collected on the menus across the sixteen HS centres or on the demographic composition of the classrooms. Lack of consistency in the menus or differences in classroom compositions may have contributed to the variability in the amount of food consumed across the centres. Conducting digital photography in the HS centre may be viewed as intrusive with the potential of influencing the typical consumption of lunch meals and the environment surrounding the lunch meals. However, there was large variation in the amount of food served and plate waste, suggesting that children's eating behaviour at the lunch meal was not altered. The amount of variability captured in food intake using this unobtrusive method has been shown in other studies ${ }^{(33,46-48,50,54)}$. The method is limited in terms of the environment in which it can be used. It has been used only to assess lunch and dinner meals in a child care or home setting and does not translate in measuring the real-life $24 \mathrm{~h}$ dietary intake of preschool children. This method can serve as a methodological foundation for incorporating more technological innovations ${ }^{(55)}$, such as cell phones using computer imaging algorithms ${ }^{(47,56)}$, for reducing the burden on respondents and research staff and to measure food intake in near real time in free-living conditions ${ }^{(50,54)}$.

\section{Conclusion}

Findings from our study showed that plate waste was high. Variation in the amounts served and consumed was substantial and the amounts served were positively associated with the amounts consumed. Finally, child characteristics influenced the amount of food served and consumed by pre-school children. Given that large portion sizes may contribute to the high prevalence of overweight among children by promoting excessive intake at meals, teaching pre-school children how to 
serve themselves appropriately sized amounts of food may help prevent obesity and reduce food waste.

\section{Acknowledgements}

Sources of funding: This research project was supported by the US Department of Agriculture (USDA)/Agricultural Research Service (ARS) through specific cooperative agreement 58-6250-6-003 and the National Cancer Institute (Grant 5 R01 CA-107545). Partial support was received from the USDA Hatch Project LAB 93951. Conflicts of interest: The authors declare that they have no conflict regarding this paper and have no involvements that might raise the question of bias in the work reported or in the conclusions, implications and opinions stated. Ethics: The study was approved by the Institutional Review Board for Baylor College of Medicine and Affiliated Hospitals. Authors' contributions: T.A.N. conceptualized the study and wrote the first draft of the manuscript. C.E.O'N. and J.A.M. substantially revised the manuscript with critical feedback. Y.L. conducted all data analyses and wrote parts of the statistical analyses section. J.E.S. and J.O.F. edited the manuscript. All of the authors listed in this paper meet the criteria set down by the International Committee of Medical Journal Editors. No one who might consider that he or she has a right to be an author has been excluded. Acknowledgements: The authors thank the USDA and National Cancer Institute for providing financial assistance. They extend a special thanks to the administration of the HS districts in Houston, Texas, i.e. Neighborhood Centers Inc., Avance and Gulf Coast, and all of the children and families who have participated in the study. Special thanks go to Sandra Lopez for coordinating the study, Lori Briones for help in preparing the manuscript, and Bee Wong for obtaining research articles.

\section{References}

1. Ogden CL, Carroll MD, Kit BK et al. (2012) Prevalence of obesity and trends in body mass index among US children and adolescents, 1999-2010. JAMA 307, 483-490.

2. Cashdan E (1994) A sensitive period for learning about food. Hum Nature 5, 279-291.

3. Birch LL (1992) Children's preferences for high-fat foods. Nutr Rev 50, 249-255.

4. Birch LL, McPhee L \& Sullivan S (1990) Conditioned flavor preferences in young children. Physiol Behav 47, 501-505.

5. Birch LL, Zimmerman SI \& Hind H (1980) The influence of social-affective context on the formation of children's food preferences. Child Dev 51, 856-861.

6. Birch LL (1979) Dimensions of preschool children's food preferences. J Nutr Educ 11, 91-95.

7. Capizzano J \& Adams G (2000) The Hours That Children Under Five Spend in Child Care: Variation Across States. Assessing the New Federalism Series B, Report No. B-8. http://www.urban.org/publications/309439.html (accessed January 2012).

8. Head Start, An Office of the Administration for Children and Families, Early Childhood Learning and Knowledge Center (2011) About Head Start. http://eclkc.ohs.acf.hhs. gov/hslc//hs/about (accessed January 2013).
9. Head Start, An Office of the Administration for Children and Families, Early Childhood Learning and Knowledge Center (2009) ABC's of Successful Menu Planning: FamilyStyle Meal Service. http://eclkc.ohs.acf.hhs.gov/hslc/ tta-system/health/Health/Nutrition/Nutrition\%20Program\% 20Staff/health_pub_12000_071406.html (accessed January 2013).

10. Freedman M \& Alvarez K (2010) Early childhood feeding: assessing knowledge, attitude, and practices of multi-ethnic child-care providers. J Am Diet Assoc 110, 447-451.

11. Rolls BJ, Engell D \& Birch LL (2000) Serving portion size influences 5-year-old but not 3-year-old children's food intakes. J Am Diet Assoc 100, 232-234.

12. Birch LL, Billman J \& Richards SS (1984) Time of day influences food acceptability. Appetite 5, 109-116.

13. Birch L, McPhee L, Sullivan S et al. (1989) Conditioned meal initiation in young children. Appetite 13, 105-113.

14. McConahy KL, Smiciklas-Wright H, Birch LL et al. (2002) Food portions are positively related to energy intake and body weight in early childhood. J Pediatr 140, 340-347.

15. McConahy KL, Smiciklas-Wright $\mathrm{H}$, Mitchell DC et al. (2004) Portion size of common foods predicts energy intake among preschool-aged children. J Am Diet Assoc 104, 975-979.

16. Huang TT, Howarth NC, Lin BH et al. (2004) Energy intake and meal portions: associations with BMI percentile in US children. Obes Res 12, 1875-1885.

17. Fisher JO, Rolls BJ \& Birch LL (2003) Children's bite size and intake of an entree are greater with large portions than with age-appropriate or self-selected portions. Am J Clin Nutr 77, 1164-1170.

18. Fisher JO, Arreola A, Birch LL et al. (2007) Portion size effects on daily energy intake in low-income Hispanic and African American children and their mothers. Am J Clin Nutr 86, 1709-1716.

19. Fisher JO, Liu Y, Birch LL et al. (2007) Effects of portion size and energy density on young children's intake at a meal. Am J Clin Nutr 86, 174-179.

20. Fisher JO (2007) Effects of age on children's intake of large and self-selected food portions. Obesity (Silver Spring) 15, 403-412.

21. Fisher JO \& Kral TV (2008) Super-size me: portion size effects on young children's eating. Physiol Behav 94, 39-47.

22. Ello-Martin JA, Ledikwe JH \& Rolls BJ (2005) The influence of food portion size and energy density on energy intake: implications for weight management. Am J Clin Nutr 82, Suppl. 1, 236S-241S.

23. Kral TV, Kabay AC, Roe LS et al. (2010) Effects of doubling the portion size of fruit and vegetable side dishes on children's intake at a meal. Obesity (Silver Spring) 18, 521-527.

24. Spill MK, Birch LL, Roe LS et al. (2010) Eating vegetables first: the use of portion size to increase vegetable intake in preschool children. Am J Clin Nutr 91, 1237-1243.

25. Bachman JL, Reedy J, Subar AF et al. (2008) Sources of food group intakes among the US population, 2001-2002. J Am Diet Assoc 108, 804-814.

26. Krebs-Smith SM, Guenther PM, Subar AF et al. (2010) Americans do not meet federal dietary recommendations. J Nutr 140, 1832-1838.

27. Ledoux TA, Hingle MD \& Baranowski T (2010) Relationship of fruit and vegetable intake with adiposity: a systematic review. Obes Rev 12, e143-e150.

28. Mendoza JA, Drewnowski A, Cheadle A et al. (2006) Dietary energy density is associated with selected predictors of obesity in US children. J Nutr 136, 1318-1322.

29. Leahy KE, Birch LL, Fisher JO et al. (2008) Reductions in entree energy density increase children's vegetable intake and reduce energy intake. Obesity (Silver Spring) 16, 1559-1565. 
30. Leahy KE, Birch LL \& Rolls BJ (2008) Reducing the energy density of multiple meals decreases the energy intake of preschool-age children. Am J Clin Nutr 88, 1459-1468.

31. US Department of Agriculture, Food and Nutrition Service (2013) Child and Adult Care Food Program (CACFP). Meal Patterns. http://www.fns.usda.gov/cnd/care/programbasics/ meals/meal_patterns.htm (accessed January 2013)

32. Hampl JS, Dixon KS \& Hall R (2003) A picture is worth a thousand words: digital photography and diet assessment. J Am Diet Assoc 103, 172.

33. Nicklas TA, O'Neil C, Stuff J et al. (2012) Validity and feasibility of a digital diet method for use with preschool children: a pilot study. J Nutr Educ Behav 44, 618-623.

34. Lohman TG, Roche AF \& Martorell R (1988) Anthropometric Standardization Reference Manual. Champaign, IL: Human Kinetics Books.

35. Kuczmarski RJ, Ogden CL, Guo SS et al. (2002). CDC Growth Charts for the United States: methods and development. Vital Health Stat 11 issue 246, 1-190; available at http://www.cdc.gov/growthcharts/

36. Fox M, Glantz F, Geitz L et al. (1997) Early Childhood and Child Care Study: Nutritional Assessment of CACFP. Final Report Volume II. Alexandria, VA: US Department of Agriculture, Food and Consumer Service, Office of Analysis and Evaluation; available at http://www.fns.usda.gov/Ora/ menu/Published/CNP/FILES/ChldCareVol2 Part1.pdf

37. Fox MK, Devaney B, Reidy K et al. (2006) Relationship between portion size and energy intake amoung infants and toddlers: evidence of self-regualtion. J Am Diet Assoc 106, Suppl. 1, S77-S83.

38. Leahy KE, Birch LL \& Rolls BJ (2008) Reducing the energy density of an entree decreases children's energy intake at lunch. J Am Diet Assoc 108, 41-48.

39. Colapinto CK, Fitzgerald A, Taper LJ et al. (2007) Children's preference for large portions: prevalence, determinants, and consequences. J Am Diet Assoc 107, 1183-1190.

40. US Department of Agriculture, Agricultural Research Service (2010) Away from Home: Percentages of Selected Nutrients Contributed by Foods Eaten Away from Home, by Gender and Age. What we eat in America: NHANES 2007-2008. http://www.ars.usda.gov/Services/docs.htm? docid $=18349$ (accessed January 2013).

41. Institute of Medicine of the National Academies, Food and Nutrition Board (2002) Dietary Reference Intakes for Energy, Carbohydrate, Fiber, Fat, Fatty Acids, Cholesterol, Protein, and Amino Acids. http://iom.edu/Reports/2002/ Dietary-Reference-Intakes-for-Energy-Carbohydrate-Fiber-FatFatty-Acids-Cholesterol-Protein-and-Amino-Acids.aspx (accessed January 2013).

42. Bucholz EM, Desai MM \& Rosenthal MS (2011) Dietary intake in Head Start vs non-Head Start preschool-aged children: results from the 1999-2004 National Health and
Nutrition Examination Survey. I Am Diet Assoc 111, 1021-1030.

43. Foundation RAG (2008) It's 12 o'clock.. What Are Our Preschoolers Eating for Lunch? An Assessment of Nutrition and the Nutrition Environment in Licensed Child Care in Los Angeles. http://cfpa.net/ChildNutrition/ChildCare/ CFPAPublications/Gilbert-LA-ChildCareLunchAssessment2008.pdf (accessed January 2013).

44. Padget A \& Briley ME (2005) Dietary Intakes at child-care centers in central Texas fail to meet Food Guide Pyramid recommendations. J Am Diet Assoc 105, 790-793.

45. Williamson DA, Allen HR, Martin PD et al. (2003) Comparison of digital photography to weighed and visual estimation of portion sizes. J Am Diet Assoc 103, 1139-1145.

46. Martin CK, Correa JB, Han H et al. (2012) Validity of the Remote Food Photography Method (RFPM) for estimating energy and nutrient intake in near real-time. Obesity (Silver Spring) 20, 891-899.

47. Martin CK, Han H, Coulon S et al. (2009) A novel method to remotely measure food intake of free-living individuals in real time: the remote food photography method. Br J Nutr 101, 446-456.

48. Martin CK, Nicklas TA, Gunturk BK et al. (2013) Measuring food intake with digital photography. J Hum Nutr Diet (In the Press).

49. Williamson DA, Martin PD, Allen HR et al. (2002) Changes in food intake and body weight associated with basic combat training. Mil Med 167, 248-253.

50. Martin CK, Newton RL Jr, Anton SD et al. (2007) Measurement of children's food intake with digital photography and the effects of second servings upon food intake. Eat Behav 8, 148-156.

51. Klesges RC, Klesges LM, Brown G et al. (1987) Validation of the 24-hour dietary recall in preschool children. J Am Diet Assoc 87, 1383-1385.

52. Baranowski T, Sprague D, Henske J et al. (1991) Accuracy of maternal dietary recall for preschool children: socioeconomic status and daycare factors. J Am Diet Assoc 91, 669-674.

53. Fisher JO, Butte NF, Mendoza PM et al. (2008) Overestimation of infant and toddler energy intake by 24-h recall compared with weighed food records. Am J Clin Nutr 88, 407-415.

54. Williamson DA, Allen HR, Martin PD et al. (2004) Digital photography: a new method for estimating food intake in cafeteria settings. Eat Weight Disord 9, 24-28.

55. Boushey C, Kerr D, Wright J et al. (2009) Use of technology in children's dietary assessment. Eur J Clin Nutr 63, Suppl. 1, S50-S57.

56. Martin C, Kaya S \& Gunturk B (2009) Quantification of food intake using food image analysis. Conf Proc IEEE Eng Med Biol Soc 2009, 6869-6872. 